\title{
Innovation and social responsibility in food ingredients market
}

\section{Luigi Bollani}

Department ESOMAS (Economic, Social, Mathematical and

Statistical Sciences),

School of Management and Economics (SME),

University of Turin,

Turin, Italy

Email: luigi.bollani@unito.it

\section{Anna Claudia Pellicelli*}

Department of Management,

School of Management and Economics (SME),

University of Turin,

Turin, Italy

Email: annaclaudia.pellicelli@unito.it

*Corresponding author

\section{Stefaan Van Dyck}

Kemin Industries BVBA,

Herentals, Belgium

Email: stefaan.vandyck@kemin.com

\begin{abstract}
This paper deals with food ingredients market. It describes some international characteristics and trends focusing on the importance of innovation to assure continuity to the business preserving the respect of environment. Particularly the social responsibility of the market companies may produce improvements in B2C, but also in B2B channels. An entrepreneurial vision is presented as a necessary link with theoretical backgrounds. An empirical analysis is also introduced to validate some conclusions.
\end{abstract}

Keywords: food ingredients market; innovation; risk aversion; social responsibility; consumer behaviour; empirical survey; multivariate statistical analysis.

Reference to this paper should be made as follows: Bollani, L., Pellicelli, A.C. and Van Dyck, S. (2018) 'Innovation and social responsibility in food ingredients market’, Global Business and Economics Review, Vol. 20, Nos. 5/6, pp.573-581.

Biographical notes: Luigi Bollani is a researcher at the University of Turin (Department of Economic, Social, Mathematical and Statistical Sciences). His main research topics fall into social statistics and sample surveys. Included among his recent publications are 'Attitudes and behaviour of adopters of 
technological innovations in agricultural tractors: a case study in Italian agricultural system', Agricultural Systems (with Cavallo et al., 2014) and 'Statistical model to investigate the contributions under flexible work conditions for workers and business', Journal of Financial Management and Analysis, Vol. 29.1 (with Tardivo, 2016).

Anna Claudia Pellicelli is an Associate Professor in Branding and in Strategic and International Marketing at the University of Turin, Department of Management). Included among her publications are Le strategie delle imprese high tech (1999) and Strategie di posizionamento nell'era digitale (2008).

Stefaan Van Dyck defended his PhD thesis in Organic Chemistry in 2001 and immediately afterwards started to work for the Kemin Animal Nutrition and Health (EMEA) as a Chemistry Manager. In 2006 he obtained an MBA at the University of Antwerp Management School and in 2008 he became a member of the Kemin Animal Nutrition and Health (EMEA) executive team with responsibility for $\mathrm{R} \& \mathrm{D}, \mathrm{QC} / \mathrm{QA}$, regulatory affairs and lab services for customers. Also in 2008, he was appointed as a Guest Professor at the University of Antwerp where he now teaches food chemistry to the Master students of chemistry. In January 2014 he moved to the Kemin Food Technologies division for Europe, Middle East and Africa in the role of Business Unit President.

This paper is a revised and expanded version of a paper entitled 'Sustainability and social responsibility in the food industry. Focus on ingredients market' presented at 9th EuroMed Conference of the EuroMed Academy of Business, Warsaw, Poland, 14-16 September 2016.

\section{Introduction}

Environmental issues have become a major concern for many industries. Consumer preferences have shifted in favour of 'environmentally friendly' goods while the need for compliance with new environmental regulations eats into capital budgets. Both product and process innovation are an inevitable component of the industrial response (Dodgson and Rothwell, 1994).

Shift in the socio-economic field (in what people believe, expect, want and earn) creates opportunities and constraints.

Legislation may open up new pathways, or close down others, for example, increasing the requirements for environmentally friendly products.

Competitors may introduce new products which represent a major threat to existing market positions. In all these ways firms need the capability to respond through product innovation (Tidd et al., 1997). Every firm has an incentive to retain the source of value creation in-house. The possible range of sources is identified to include cost minimisation, product market strategy and core competence.

There is always very little disagreement among economists about the importance of innovations for long-term economic growth. From Adam Smith, Ricardo, Marx, Marshall, Schumpeter and Keynes there is virtual unanimity that the long term growth of productivity is intimately related to the introduction and diffusion of technical and organisational innovations (Dodgson and Rothwell, 1994). 
There is a wide range of factors associated with successful innovation which appear to be common to all sectors of manufacturing, with different weightings in different sectors. Success is multi-factored and it is inextricably linked to the qualities and abilities of those involved in managing the process. Strategies associated with successfully innovative firms similarly are multi-dimensional emphasising the importance of both technological and marketing factors (Rothwell, 1986).

The food ingredients business is often driven by a very technical sales process. Technical teams of the customer are often involved in many projects and are easily interested in something that is new. The start of the development process is of course furthest away from the sale to the end user.

Von Hippel $(1977,1988)$ focused attention on the role of the user in the innovation process in part to determine how an innovating firm goes about acquiring an accurate understanding of user need. The pale grey area in Figure 1 represents a win-win condition.

Figure 1 Return for user and producer (ROII)

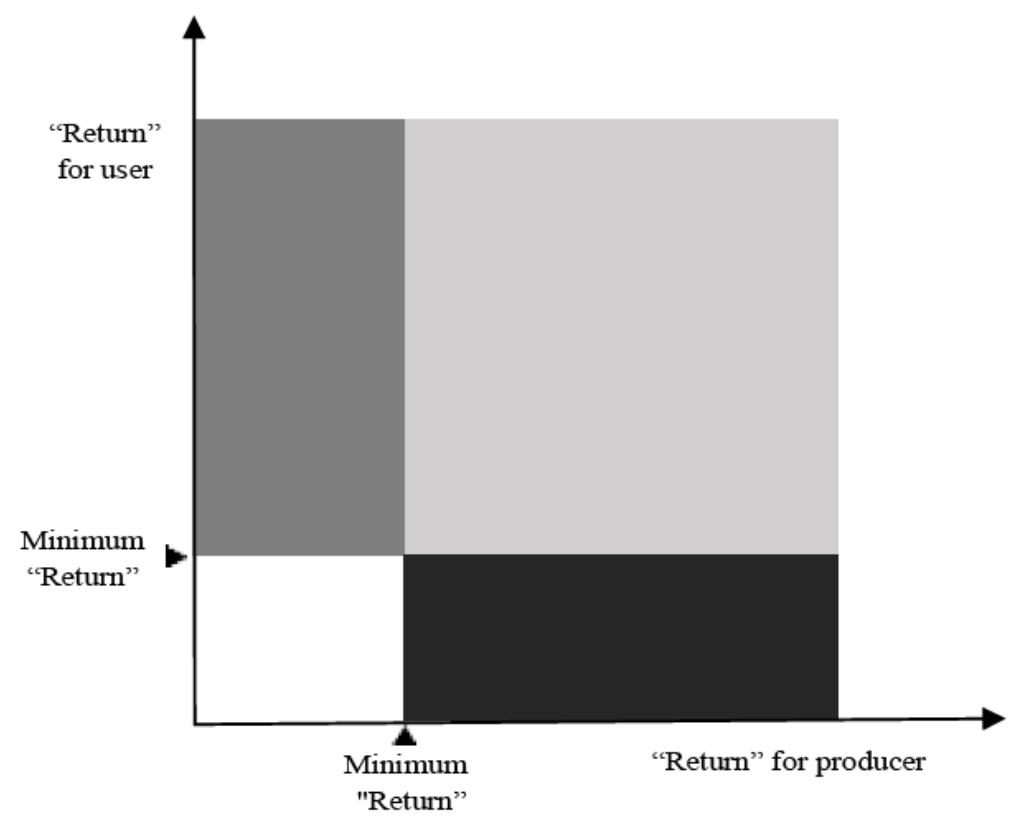

Notes: Adequate 'return' for:

$\square$ innovation by user.

innovation by producer.

Source: Von Hippel (1977)

\section{Innovation as a key factor in ingredients market}

As in many other industries, innovation is a key criterion to develop successful business in the ingredient's market. Nevertheless, there are specific challenges in a B2B environment. When bringing technical innovation to the market this may not always be 
visible for the end user and therefore these innovations do not necessarily pull their entire value through the value chain (Tidd et al., 1977).

This can be demonstrated with an example of a technical ingredient: Suppose that the product development department of margarine company is able to improve one of its ingredients, more specifically an emulsifier (used to avoid that the water and oil fraction in the margarine separate so that the margarine remains solid enough, but spreadable). The alternative ingredient has shown that it can be used at lower dosage resulting in a lower cost in use. This formulation change gives immediate value as a cost saving to the manufacturer, but how would this added value then be communicated to the end user? The appearance and the taste of the product have not changed. Only when the margarine company would reduce its selling price, there would be a direct benefit for the end user, albeit only a monetary benefit. Besides price there would be no other change that would differentiate the margarine, opening the route to commoditisation.

The food ingredients business is often driven by a very technical sales process. A complete understanding of the ingredient, as well as its function and application in a wide range of different food products is required. Consequently, the first point of contact where the sales process would be found in the new product development team, quality control and quality assurance or research and development (Dixon and Adamson, 2011).

Technical teams of the customer are often involved in many projects and are easily interested in something that is new. The start of the development process is of course furthest away from the sale to the end user. The success of product development by and large depends on how well a company can bridge the customer needs and customer value with the open mind that a product development group needs to have in order to also discover initially very non-obvious or unfeasible ideas that can lead to breakthrough innovation. In practice many technical sales projects start enthusiastically in a technical group, but as the project progresses there are often many marketing and sales hurdles that will stop a project. True ingredient innovation will comprise both a technical benefit for the food producer as well as a tangible improvement that the end user of the food product can experience. These innovations carry through in the entire value chain and create benefits and differentiation that reach far beyond a simple cost saving.

\section{The social responsibility choice in a B2B market: social responsibility in ingredient's market}

One could assume that the way innovation needs to carry through the entire value chain, that this would also be the case for social responsibility. However here a clear differentiation needs to be made between ingredients that represent a large portion of the food product versus micro ingredient. A very concrete and recent example is the issue around the use of palm oil. The biggest consumer concern was driven by animal welfare and preservation of nature. In order to grow palm trees there has been significant pressure on the tropical forests in Malaysia and Indonesia. Certain areas of forest had been cleared of the original vegetation by 'controlled' forest fires in order to plant palm trees for the oil production. Besides the destruction of rain forest also photos of orangutans that were killed or heavily burnt by these fires were published in the media.

The first companies that hit the eye of the storm were of course companies that were known for their high utilisations of palm oil in their food products. As a result, food companies and palm oil suppliers have worked on a solution through the formation of the 
so-called 'round table for sustainable palm oil (RSPO)' in order to guarantee that the palm oil that is used by associated food companies is produced in a responsible way, without harming animal welfare and considering many other parameters related to sustainability.

In a second wave, there were also food producers that started to look at some of their micro ingredients if these also included palm oil, or if it had been used in the process to produce these ingredients. There are many functional ingredients that are used at very low dosage such as antioxidants (often used in concentrations below $0.1 \%$ ) and emulsifiers. Suppliers of these ingredient where then requested to provide information on the potential use of palm oil anywhere in the process and to replace to an RSPO or a palm-free alternative

This example illustrates that social responsibility and sustainability is often a requirement that originates from a clear consumer demand and then moves top down. From consumer and consumer organisations to retailers and from there further down to the food manufacturers and initially the suppliers of their main ingredients. Only at a later stage the 'smaller' ingredients may also come into the picture.

Is it important to propose to the final market - through a B to B channel - some social responsibility peculiarities?

The long term vision in a family business closely relates to the importance such companies give to social responsibility and sustainability. The main question is if these principles then also translate to customer value. Certainly in the B2B environment of the food ingredients industry, it is not easy to also translate these values to the end user, i.e. the consumer of the food product.

Kemin has found ways to bring the value of the sustainability its ingredients to the different levels of the entire value chain. An example is the Kemin rosemary extracts which is used as functional ingredient in food, pet food and animal feed for its flavour and antioxidant properties. For the antioxidant applications the use of rosemary extract is a way to move from traditional antioxidants that are produced synthetically to a sustainable and renewable source. This value could be immediately valid for the end consumer who is interested in more natural and renewable ingredients in his food. Although there is an immediate benefit to comply with a specific consumer preference for renewable products, there is no immediate tangible benefit for the food producer. Actually, the renewable product is more expensive, so how much is the consumer willing to pay as a premium, or will the food producer need to sacrifice margin?

Successful market adoption for these type of sustainable ingredients requires a clear added value for all players in the value chain. As such, sustainability is not the most important factor for many food producers. They have many other issues to tackle. Kemin's approach was to clearly focus on these different needs and to incorporate additional benefits into the product which have specific value for the intermediates in the value chain. In the case of the rosemary extract, Kemin decided to become totally vertically integrated in the production of rosemary antioxidants. This included the creation of a 'specialty crop development' group that focused on the development of the optimal rosemary plant through traditional breeding techniques. Then this plant was further cultivated and harvested by Kemin. Also the extraction of the desired compounds from the plant material, as well as its formulation into a finished product is done by Kemin. Due to the complete vertical integration it was possible for the company to produce a more potent rosemary extract, that performs extremely consistently (reduced 
natural variation compared to extracts from rosemary harvested in the wild and not optimised for its desired properties). Moreover, because of the complete control of the entire production chain, there is an extreme level of control over the quality and traceability of the ingredient. The risk to have any undesirable substances in a food product is one of the most important worries of a food manufacturer. The fact that Kemin was able to develop a sustainable product brought immediate value to the consumer, but the addition of the quality and consistency element has incorporated a key added value for the food producers.

\section{Some consumer perceptions on social responsibility and quality of food}

In order to analyse from a marketing point of view the consumer's perception in social responsibility, a key factor is to measure the influence of different variables, each concerning responsibility in some different sense, in the buying decision. This evaluation is very important for selling companies also inside different targets, in which consumers may be included.

Following this research direction, a pilot survey was conducted, using a questionnaire mainly distributed in the north of Italy and generally tested through different channels like word of mouth, social networking and online forums concerning the food sector.

The sample, involving the responses to the questionnaire, consists of two-thirds of women and one-third of men, while the total responses amounted at nearly two hundred consumers.

In the questionnaire the following variables were inquired to investigate their influence on the consumer buying choices: environment, protection, preservatives, health and fashion. The respondent had to put these variables in comparison by evaluating each of them with a five point Likert scale.

So the analysis of the whole contest involves the relationships joining the five considered variables. To synthesise them and to sketch the global framework in only two dimensions, a principal component analysis (PCA) was performed and then shown in Figure 2.

The PCA chart explains, with both the first and the second dimensions, the $74.05 \%$ of the global variance contained inside the data and so it allows a satisfying representation of the joined linear correlation structure.

Correlations can be graphically observed considering the amplitudes of the angles formed by the different arrows: a very acute angle means a high direct linear correlation between the two variables (arrows) that form that angle, a right angle means a linear absence of correlation and an obtuse angle means an inverse linear correlation.

The chart figures out that some variables are closely correlated and that they consequently play nearly the same rule in the consumer perception (that is, the importance attributed by a consumer to any of these variables is typically reflected in all the other).

It can be noted that three variables, and in particular 'way of producing', 'preservatives absence' and 'environment respect', are strongly related to each other and they are also correlated with 'protection of health', although with a lower intensity that they have among them.

All these variables globally correspond quite well to the first (horizontal) axis of the PCA chart, that can be summarised in the importance assigned by the consumers to a 
production of quality food, carried on with respect for the environment and paying attention to limit the use of preservatives and to protect the human health.

Below this new synthetic variable will be simply called 'dim1' or 'quality, health and environment' and it grows from the left to the right in the map, together with the increase of the importance attributed by the consumers to these topics.

Figure 2 PCA map: drivers that influence purchases

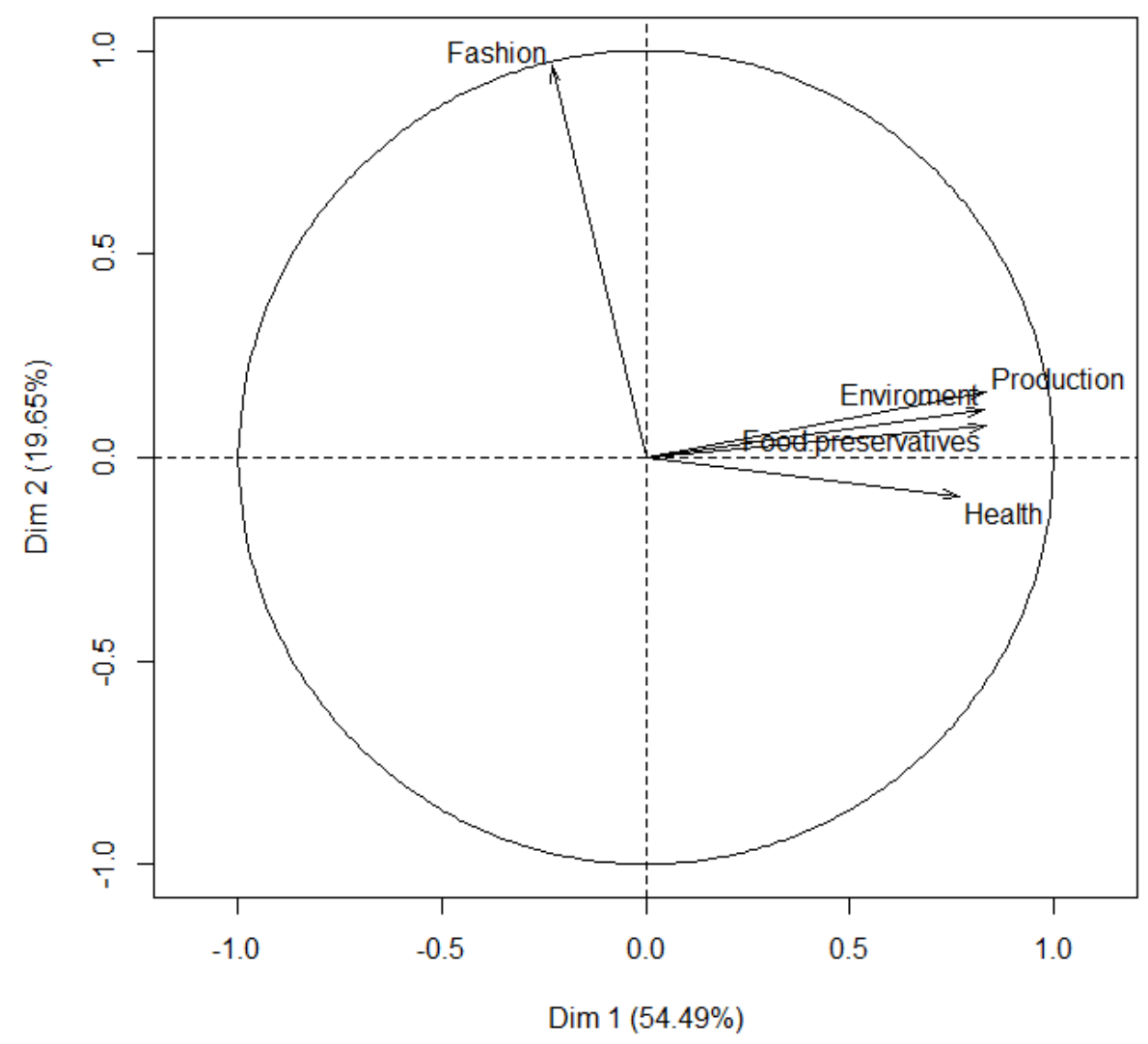

Considering the variable 'fashion food', it is just inversely correlated with 'dim1' and a little more inversely correlated in particular with 'protection of health' (that is, who looks more fashionable tends to assign a bit less importance to salutary characteristics of food).

Anyway the variable 'fashion food' has a direction not too far from the second (vertical) dimension of the chart, which is constructed to be uncorrelated with the first (horizontal) one. So the dependence of a choice of 'fashion food' by the importance assigned to 'quality, health and environment' is low. That is, there is not a very different easiness to be sensible to fashion in food choices for people who assign different levels of importance to 'quality, health and environment', although an attributed low importance on these topics (and above all on health) may suggest a little tendency to look more at fashion. It is also interesting to refer these general considerations to specified targets, in order to achieve a better comprehension of different subgroups of consumers. 
In a second map, Figure 2, the same dimensions of Figure 1 are represented: so the importance attributed to 'quality, health and environment' increases from the left to the right of Figure 1 and the importance attributed to 'fashion food' roughly increase from the bottom to the top.

Inside the map, instead of the original variables, the centre positions of some target categories are represented. Any category includes a corresponding group of sample consumers and, because each of them has a position on the map according to the answers given to the questionnaire, it is possible to represent a mean profile point of that group by the centre of the coordinates of the point (consumers) included in it. In Figure 3, the positions of the sample divided by sex and, separately, by a classification of age is shown.

Figure 3 PCA map: target groups centre positions

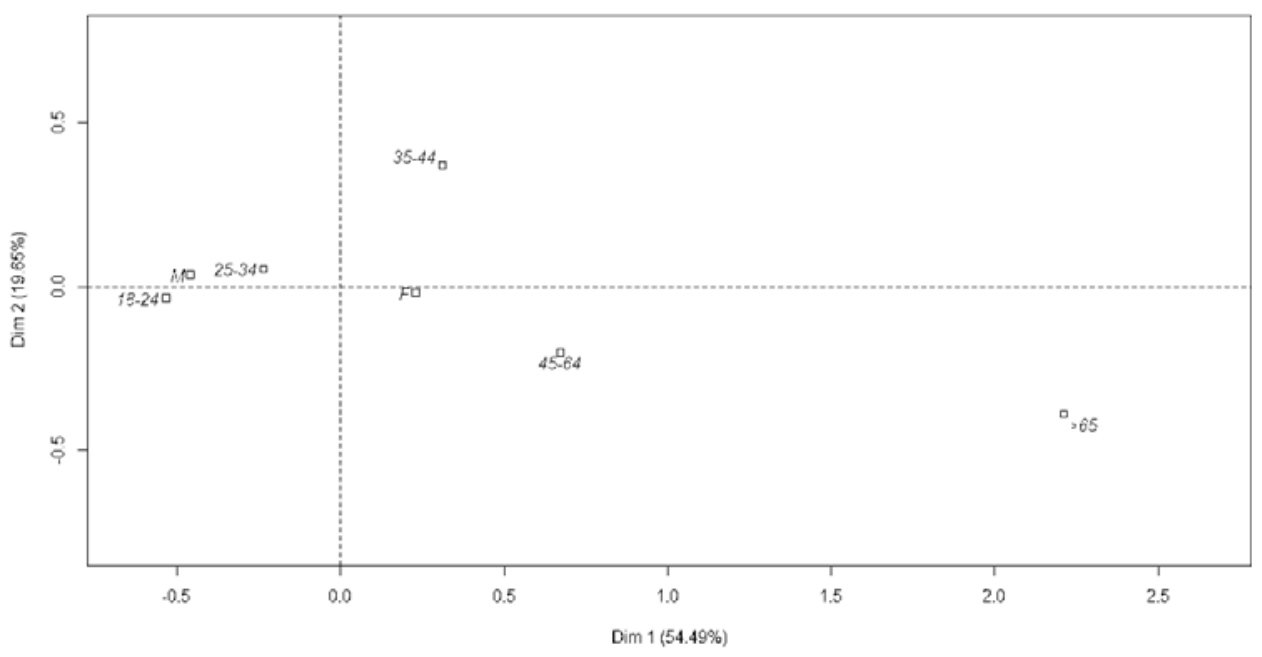

Considering sex, females are positioned further to the right than males (and roughly at the same medium level on the vertical axis): so the female target assigns on average more importance to 'quality, health and environment' than the male target (because, as stated in Figure 2 comment, the higher values for these topics are on the right of the map, following the increase of dim1). This behaviour may suggest that women, the main purchasing managers, are more interested to some specific characteristics of foods such as naturalness and quality.

Also considering the age, the different classes move on Figure 1 from the left to the right with increasing age: so young people assign on average less importance to 'quality, health and environment' than the elder ones. Clearly a concrete preference for these topics may require a larger budget, not always available from young people. Moreover, above all young people usually improve their knowledge and awareness with increasing age, while, thinking to elderly people, a good quality of food may become necessary for health.

Differently by sex, age classes do not have the same value on the vertical axis. The points represented further down, like 45-64 or even more $>64$, show a less sensibility to fashion, which is more considered in the age class 35-44 (this accordingly with the roughly bottom up direction of the variable 'food fashion', commented on Figure 2). 
These poll results represent a possible starting point for a discussion about the consumer orientation towards new paradigms, expressed through target behaviours.

\section{Conclusions}

Nowadays the process of innovation, increasingly necessary for companies to play successfully in the market, must take in account the increase in consumer preference towards ecological goods and the changes in the legislation in that direction, according to each Country, but important to consider together, because of the globalisation of trade.

These general considerations are particularly important for food and ingredients industry, as shown by many authors, but also pointed out in this document to be direct evidence of the entrepreneur, who may advance the process of reorganising information necessary to integrate recent events in the literature.

An important aspect that mainly involves large companies refers to the B2B sector, for which the effort to produce ecological goods may appear to be less recognised by the final consumer. In contrast, some answers have been reported describing relevant business experience, extended to the entire supply chain.

\section{Acknowledgements}

The authors thank Roberta Polillo and Valentina Teppati Gac for data management and the contribution made during the preliminary work.

\section{References}

Dixon, M. and Adamson, B. (2011) The Challenger Sale: Taking Control of the Customer Conversation, Penguin Publishing Group.

Dodgson, M. and Rothwell, R. (Eds.) (1994) Handbook of Industrial Innovations, Edward Elgar Publishing.

Fiocca, R. and Snehota, I. (1986) 'Marketing e alta tecnologia', Sviluppo e Organizzazione, Tidd, J., Bessant, J. and Pavitt, K. (1997) Managing Innovation: Integrating Technological, Market and Organizational Change, John Wiley \& Sons Ltd, Chichester, England.

Rothwell, R. (1986) 'The role of small firms in the emergence of new technologies', in Freeman, C. (Ed.): Design, Innovation and Long Cycles in Economic Development, pp.231-248, Francis Pinter, London.

Tidd, J., Bessant, J. and Pavitt, K. (1997) Managing Innovation: Integrating Technological, Market and Organizational Change, John Wiley \& Sons Ltd, Chichester, England.

Von Hippel, E. (1977) ‘Has a customer already developed your next product?’, Sloan Management Review, Winter 1977, Vol. 18, No. 2.

Von Hippel, E. (1988) The Sources of Innovation, Oxford University Press, New York. 